\title{
EXPERIMENTAL INVESTIGATIONS OF THE METHOD OF DETERMINATION OF OPTIMAL CONTROLLER SETTINGS
}

\author{
Maryna Loriia \\ Department of Electronic Devices \\ East Ukrainian National University named after Vladimir Dal \\ 59 a Central ave., Severodonetsk, Ukraine, 93400 \\ atp01@ukr.net
}

\begin{abstract}
A method for finding the optimal PID controller settings is proposed, which takes into account all the shortcomings of the most common engineering methods for finding controller settings. The method is characterized by: simplicity and versatility, which allows determining the optimal controller settings for one iteration; highly accurate identification of the control object, taking into account its nonlinearity, does not require an active experiment, provides improved dynamic properties of systems.

Tuning parameters of controllers are found by the proposed method of finding the optimal settings of the controller and the most common engineering methods for finding the settings of controllers for ACS control objects in the production of nitric acid. In addition to the examples given, a number of control objects with varying degrees of oscillation and inertia are investigated. A comparative analysis of the proposed method with the most common engineering methods for finding controller settings for ACS control objects in the production of nitric acid is performed. The analysis shows that the controller parameters found by the proposed method significantly improve the dynamic properties of the system (the overshoot decreased by 10 times, the regulation time decreased by about $30 \%$, the static and dynamic errors decreased by $2-3$ times).
\end{abstract}

Keywords: second order link, controller settings, regulation time, identification algorithm, transient process, delay time.

\section{Introduction}

Market globalization is becoming comprehensive and this means that in order to stay in business, manufacturing industries need to pay more attention to quality and efficiency issues. In turn, this focuses on the development of advanced control systems so that the processes flow better. In particular, improved management is the key to improving technology. This provides: improved product quality, minimizing losses, protecting the environment, increasing productivity for installed capacity, increasing production, postponing costly upgrades to management facilities and higher safety margins.

However, in most cases, when changing the characteristics of the object and require reconfiguration of systems. Such cases include various kinds of switching, changes in the characteristics of raw materials and materials, incoming changes caused by the variable mode of operation of objects, the properties of actuators and regulatory bodies, the interdependence of the circuits in multidimensional systems.

At present, operational personnel do not have methods suitable for industrial conditions necessary for recalculating controller settings. Under operating conditions, the only way out is weakening the controller settings, thus achieving a reduction in the mutual influence of the circuits, ensuring the necessary stability margin under any possible object operation modes. The quality of the systems is obviously much worse, and the profits are much lower than those achievable with the settings corresponding to the characteristics of the object.

Many of the quality improvement methods that are proposed by management theory are practically unsuitable for industrial environments. So the methods associated with increasing the order of control devices, providing an increase in quality, reduce the region of stability in the parameter space of the object model.

As a result, we have such a difficult situation (typical statistics for most enterprises):

$-10-90 \%$ of the contours are in manual mode;

$-30 \%$ control valves with serious problems;

$-30 \%$ of ACS set up completely wrong; 
- $40 \%$ of contours with fluctuations; $30 \%$ unsuitable regulation organization; $85 \%$ non-optimal settings;

$-75 \%$ of controllers only increase instability.

The overwhelming majority of ACSs operating in enterprises have enormous untapped potential. This potential can be "raised" at the expense of not technological measures, but at the expense of increasing the operation efficiency of these systems, optimal tuning, the main ACS devices, and controllers.

Therefore, today the task is very relevant, the development of reliable methods for finding the optimal controller settings, which would significantly improve the ACS quality.

\section{Materials and methods}

The results obtained in $[1,2]$ are experimentally confirmed. The object of research is the production of nitric acid. The subject of research is the elements of the production management system of nitric acid. The study of ACS control objects and settings PID-controllers are carried out theoretically using a computer and experimentally; using the theory of mathematical modeling and the theory of optimal control for the development and study of mathematical models of control objects and the optimal controller settings; using the methods of mathematical statistics in the processing of experimental results. The study of mathematical models and systems of automatic control of control objects in the production of nitric acid is carried out using modern software: TRACE MODE 6.08 SCADA-systems, MS Excel 2013 Maple 17, MathCAD 15.

\section{Investigation of the method for finding the optimal controller settings}

The distributed control system was implemented in the TRACE MODE SCADA system, the executive modules of which ensured the real-time operation of the system. The system can be used in the union, consisting of several process ACS located in different sites. Internet channels, industrial buses, serial interfaces, radio networks and dial-up telephone lines, as well as support for workplaces of mobile employees (for example, service personnel) working out of the office were used as data transmission channels. Employees can exchange data via GSM operators through pocket computers, laptops, the web, or even through a simple cell phone. TRACE MODE also allows to use GSM networks and for remote control and data collection of geographically distributed oil production facilities, for example, using GSM modems, it is possible to reach remote field facilities.

A distributed control system for the production of nitric acid (Fig. 1) has been developed, which, due to the implementation of the method for finding optimal controller settings (OCS) at the middle level, has ensured the ACS optimal operation. To ensure optimal ACS operation of distributed control system, a method for finding an OCS was implemented at an average level [3].

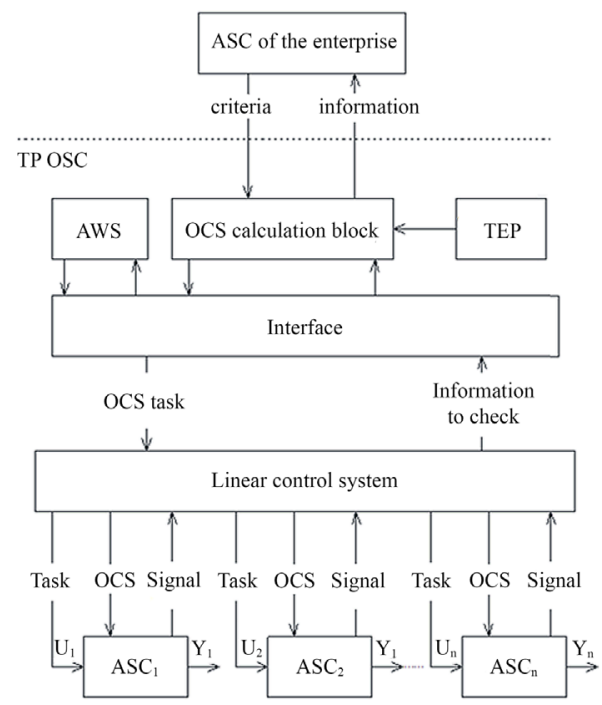

Fig. 1. Structurally-functional diagram of distributed control systems 
The main requirements for calculating the settings of the controller are simplicity, reliability, versatility, accuracy. The obtained optimal settings of the controller, which are not subject to further adjustment, should provide the ACS with such properties as accuracy, stability margin and proper speed. In many cases, known methods of searching for controller settings do not satisfy such requirements and, despite their simplicity, they have a number of significant drawbacks, namely:

- finding the MM of the control object and further determining the settings of the controller by conducting an active experiment on the object itself can lead to loss of quality of the finished product, damage to raw materials, catalysts, and even to emergencies, including fires, explosions, emissions of harmful substances to the environment;

- the control object is described by polynomials, do not take into account their nonlinearity;

- to the formulas for finding the settings of the controllers that do not include optimization indicators, that is, it is impossible to say in advance what system of optimality criteria the transition process to meet with given controller settings;

- the absence in the design formulas of the quality indicators of the transition process leads to the fact that in practice it is necessary to manually change the controller settings obtained by this or that method so that the transition process meets the control standards for a particular technological process;

- lack of universality of existing methods. The application of a specific method becomes impossible if its main calculated indicator is missing and is applied only for certain types of controllers and control objects.

Without taking into account these features of the methods, it is impossible to further improve the methods for determining the optimal controller settings for systems and objects of various types, and to improve their dynamic properties.

All these drawbacks are taken into account by the proposed method for finding the optimal controller settings [4], which combines two algorithms: an algorithm for identifying model parameters using global extrema of dynamic characteristics [4] and an algorithm for finding optimal controller settings using a quadratic optimization function $[5,6]$ :

- to identify the control objects and further determine the optimal settings of the controller, a passive experiment is conducted in an open loop, since in this case there is no possibility of taking the system out of stability;

- non-linearity of the control object is taken into account, depending on the type of the transition process, by the corresponding equation of the transition function of the second-order link [7]. In this case, the approximation of the transition function of the control object is performed using the dynamics of the transition process, described by such parameters as speed, acceleration, acceleration speed, etc., which are derived from the output signal with respect to time;

- to enter optimization indicators and quality indicators into formulas for finding optimal controller settings, we use the formula of a quadratic integral criterion, which is unimodal function for most processes and, as a single numerical value, gives a generalized estimate of the attenuation rate and the deviation value of the controlled variable. This integral determines the square of the plane between the task and the transition curve, and also depends on the controller tuning parameters;

- the versatility of this method lies in the fact that the optimal ACS settings are found for any types of transient processes of control objects and controllers, and there is no such thing as a calculated indicator in it.

The method is based on the fact that the acceleration curve of the control object is analyzed, its character is determined for approximating the transition function of the system by a second-order link with a delay time at characteristic points using the nonlinear least squares method. The equations found in this way are then used to find the optimal controller settings by quadratic integral criterion. The search for optimal controller settings is to find such controller parameters for which the quadratic integral criterion (the square of the dynamic error) would be 
minimal. To search for the extremum of the optimization function, let's use the conjugate gradient method. The values found in this way will be the optimal controller settings $[9,10]$.

To illustrate the work, a comparative analysis (Fig. $\mathbf{2}-\mathbf{5}, \boldsymbol{b}-\boldsymbol{d}$ ) of the proposed method for finding the optimal controller settings (in the figure under 1 ) and widely used in engineering practice of the triangle method (in the figure under 2), Ziegler-Nichols method $(\mathrm{Z}-\mathrm{N}$ ) (in the figure under 4) and the CHR method (in the figure under 3). The P, PI, and PID controllers of single-circuit ACS for aperiodic control objects are calculated using the example of the acceleration curves of the purge column in the production of nitric acid through the channel consumption of nitric acid $\rightarrow$ level in the column (Fig. 2, a) [8].
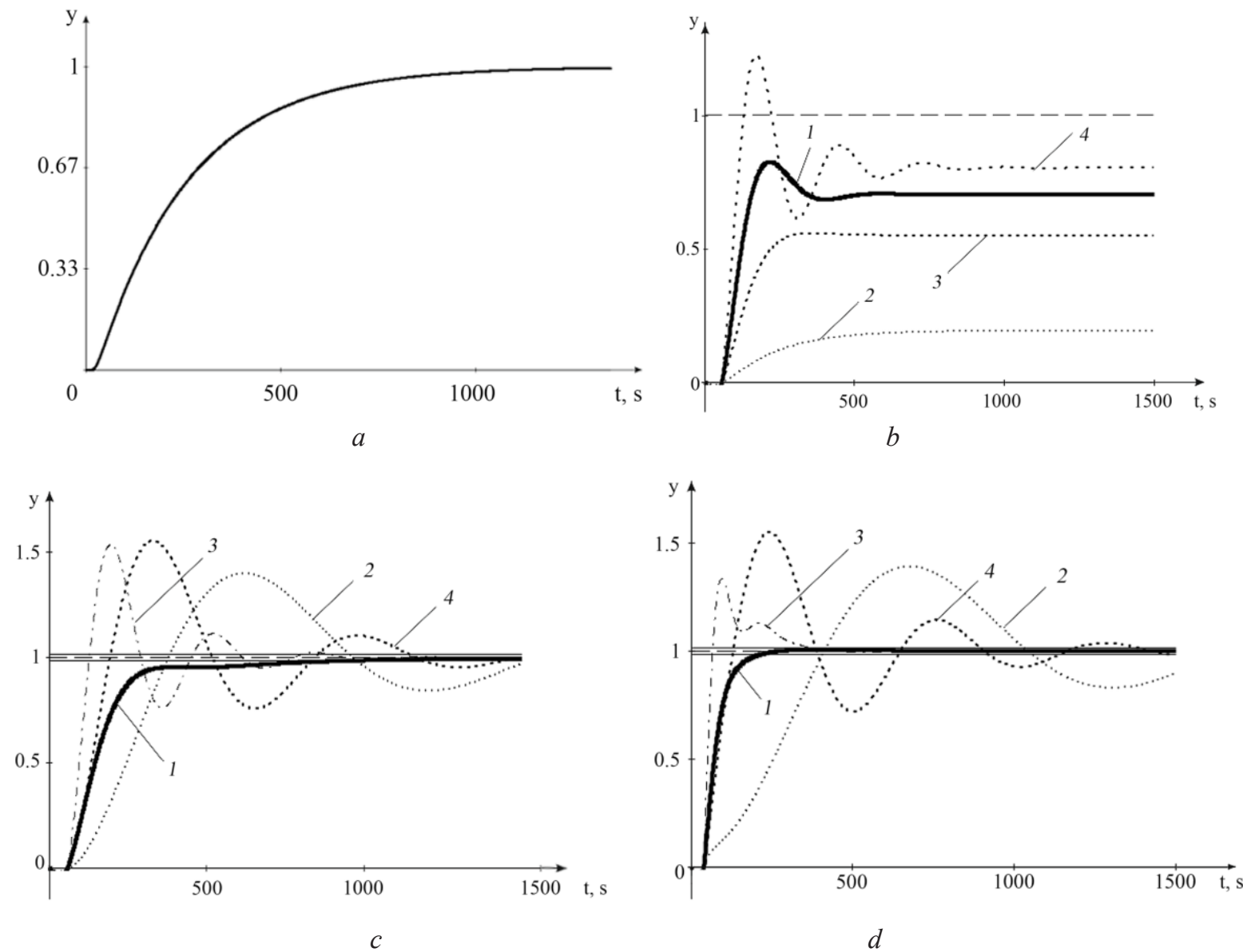

Fig. 2. ACS TP of the purge column:

$a-\mathrm{CO} \mathrm{AC} ; b-\mathrm{ACS}$ TP with P controller;

$c$ - ACS TP with PI controller; $d$ - ACS TP with PID controller

The quality indicators of ACS transients (overshoot $\sigma$, regulation time Tc, static $\Delta_{\text {st }}$ and dynamic J errors), in which the controller settings were calculated using the proposed method for finding the optimal controller settings, as well as by the triangle method, the Z-N method and the CHR method are given in comparative Tables $\mathbf{1 , 2}$.

From the analysis of the research results (Fig. 2, $\boldsymbol{b}-\boldsymbol{d}$ and Tables 1, 2), it is possible to state the improvement of the dynamic properties of the system when using the optimal controller settings calculated by the proposed method compared to the most common engineering methods of searching the controller settings for ACS with aperiodic and oscillatory parameters control objects (reduction of overshoot by an order of magnitude, regulation time and dynamic error, reduction of the static system error by 2-3 times). 
Table 1

Comparative table of the ACS operation quality for aperiodic CO

\begin{tabular}{|c|c|c|c|c|c|c|c|c|c|}
\hline \multirow{2}{*}{$\begin{array}{l}\text { Method for find- } \\
\text { ing controller } \\
\text { settings }\end{array}$} & \multirow{2}{*}{ Regulation law } & \multirow{2}{*}{ Control object } & \multicolumn{3}{|c|}{ Controller settings } & \multicolumn{4}{|c|}{ Regulation quality indicators } \\
\hline & & & Kp & Ti & Td & $\sigma$ & $\Delta_{\text {st }}$ & $\mathbf{T p}$ & $\mathbf{J}$ \\
\hline Proposed method & P controller & Purge column & 2.39 & $\infty$ & 0.00 & 17.26 & 29.52 & 465.45 & 148.04 \\
\hline Triangle method & & & 0.24 & $\infty$ & 0.00 & 0.00 & 80.39 & 816.34 & 665.90 \\
\hline $\mathrm{Z}-\mathrm{N}$ methods & & Purge column & 4.12 & $\infty$ & 0.00 & 52.36 & 19.52 & 765.26 & 130.18 \\
\hline CHR methods & & Gas reactor & 1.24 & $\infty$ & 0.00 & 1.31 & 44.70 & 202.83 & 273.18 \\
\hline Proposed method & $\mathrm{P}$ controller & & 1.14 & $\infty$ & 0.00 & 45.90 & 46.72 & 27.09 & 13.69 \\
\hline Triangle method & PI controller & & 0.57 & $\infty$ & 0.00 & 25.77 & 63.79 & 18.33 & 14.60 \\
\hline $\mathrm{Z}-\mathrm{N}$ methods & & Gas reactor & 1.78 & $\infty$ & 0.00 & 83.71 & 35.93 & 69.26 & 17.04 \\
\hline CHR methods & & Purge column & 0.53 & $\infty$ & 0.00 & 15.47 & 65.15 & 18.28 & 12.97 \\
\hline Proposed method & & & 1.62 & 187.95 & 0.00 & 0.00 & 0.00 & 959.79 & 124.97 \\
\hline Triangle method & & & 0.29 & 135.56 & 0.00 & 40.09 & 0.00 & 2564.73 & 247.94 \\
\hline $\mathrm{Z}-\mathrm{N}$ methods & & Purge column & 3.71 & 60.28 & 0.00 & 53.47 & 0.00 & 895.26 & 122.30 \\
\hline CHR methods & & Gas reactor & 1.44 & 56.36 & 0.00 & 55.50 & 0.00 & 1709.88 & 176.51 \\
\hline Proposed method & PI controller & & 0.66 & 7.57 & 0.00 & 0.00 & 0.00 & 32.45 & 5.24 \\
\hline Triangle method & PID controller & & 0.68 & 6.07 & 0.00 & 5.66 & 0.00 & 24.05 & 5.01 \\
\hline $\mathrm{Z}-\mathrm{N}$ methods & & Gas reactor & 1.60 & 6.24 & 0.00 & 37.87 & 0.00 & 60.54 & 5.66 \\
\hline CHR methods & & Purge column & 0.62 & 5.84 & 0.00 & 8.46 & 0.00 & 24.53 & 5.11 \\
\hline Proposed method & & & 3.07 & 85.01 & 95.58 & 0.00 & 0.00 & 219.48 & 73.98 \\
\hline Triangle method & & & 0.20 & 135.56 & 30.12 & 39.12 & 0.00 & 2805.33 & 241.60 \\
\hline $\mathrm{Z}-\mathrm{N}$ methods & & Purge column & 4.95 & 27.40 & 167.68 & 33.43 & 0.00 & 372.91 & 80.15 \\
\hline CHR methods & & Gas reactor & 2.47 & 27.40 & 83.84 & 54.81 & 0.00 & 1598.62 & 129.71 \\
\hline Proposed method & PID controller & & 0.68 & 5.88 & 0.89 & 0.48 & 0.00 & 15.78 & 4.30 \\
\hline Triangle method & & & 0.47 & 6.07 & 1.35 & 5.64 & 0.00 & 31.55 & 4.61 \\
\hline $\mathrm{Z}-\mathrm{N}$ methods & & Gas reactor & 2.14 & 2.84 & 3.25 & 60.73 & 0.00 & 30.37 & 4.62 \\
\hline CHR methods & & & 1.07 & 2.84 & 1.62 & 14.14 & 0.00 & 23.71 & 3.48 \\
\hline
\end{tabular}


Table 2

Comparative table of the ACS operation quality for oscillatory $\mathrm{CO}$ oscillatory

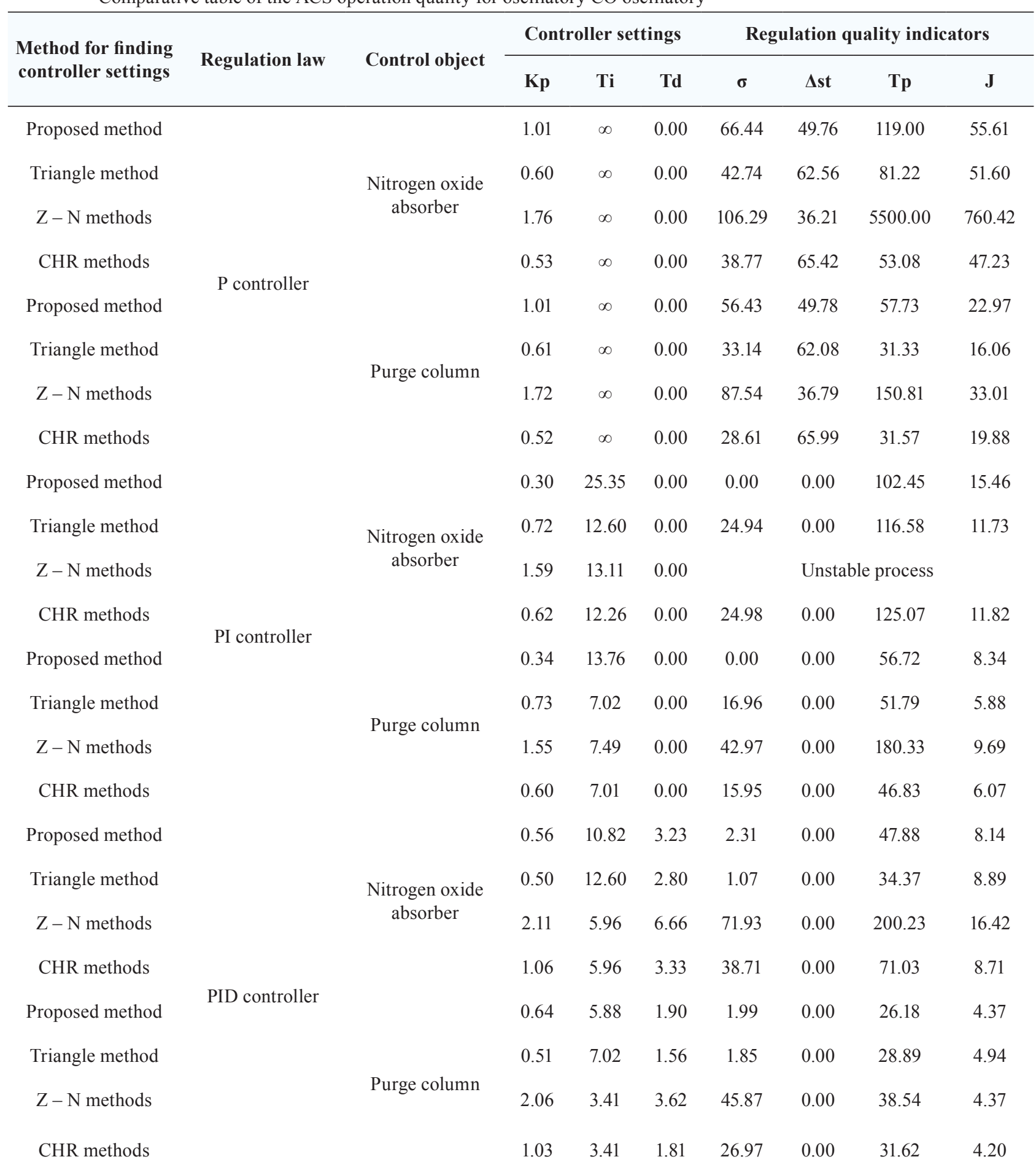

\section{Discussion of the results of an experimental research of the method for finding the optimal controller settings}

As a result, it is found the optimal settings of the PID controllers for the ACS control objects in the production of nitric acid using the developed experimental-theoretical method of finding the optimal settings of the PID controller. Simplicity and versatility allows to determine the optimal settings for the PID controller in one iteration. The method is characterized by a high accuracy of 
identification of control objects with regard to their nonlinearities, and also does not require an active experimen: improved dynamic properties of ACS (reduction of overshoot by an order of magnitude, regulation time and dynamic error, reduction of the static system error by 2-3 times) as a result of which safer process management.

The developed method of finding the optimal settings of the PID controller can also be applied when finding the optimal settings of the PID controller for other ACSs, in which control objects can be identified by a second-order link with a delay.

\section{Conclusions}

A distributed control system for the production of nitric acid is developed, due to the implementation in it at an average level of the method of finding OSC, has ensured optimal ACS operation.

A method for finding the optimal PID controller settings is proposed, which takes into account all the shortcomings of the most common engineering methods for finding controller settings. It is characterized by: simplicity and versatility, which allows to determine the optimal controller settings for one iteration; highly accurate identification of the control object, taking into account its nonlinearity, does not require an active experiment, provides improved dynamic properties of systems.

Regulation parameters of controllers are found by the proposed method of finding the optimal controller settings and the most common engineering methods for finding the settings of controllers for ACS of control objects in the production of nitric acid. In addition to the examples given, a number of control objects with varying degrees of oscillation and inertia are investigated.

A comparative analysis of the proposed method with the most common engineering methods for finding controller settings for ACS control objects in the production of nitric acid is performed. It shows that the controller parameters found by the proposed method significantly improved the dynamic properties of the system (overshoot decreased by 10 times, regulation time decreased by about $30 \%$, static and dynamic errors decreased by 2-3 times).

\section{References}

[1] Ananiev, M. V., Tselishchev, O. B., Loriya, M. H., Yelisieiev, P. Y. (2010). Optymalne nastroiuvannia rehuliatora za kvadratychnoiu optymizatsiynoiu funktsieiu. Visnyk Skhidnoukrainskoho natsionalnoho universytetu imeni Volodymyra Dalia, 6, 134-141.

[2] Ananiev, M. V., Tselishchev, O. B., Loriya, M. H., Yelisieiev, P. Y., Yerokhina, O. V. (2010). Identyfikatsiya obiektiv keruvannia. Vymiriuvalna ta obchysliuvalna tekhnika $\mathrm{v}$ tekhnolohichnykh protsesakh, 2 (36), 178-181.

[3] Ananiev, M. V., Tselishchev, O. B., Loriya, M. H., Yelisieiev, P. Y. (2011). Aproksymatsiya perekhidnoi funktsiyi obiekta keruvannia lankoiu druhoho poriadku. Vymiriuvalna ta obchysliuvalna tekhnika v tekhnolohichnykh protsesakh, 2, 209-213.

[4] Karakawa, K., Abe, N., Ichihara, H. (2002). Joint design method of closed-loop identification and IMC structure for temperature control system with time delay. Proceedings of the 41st SICE Annual Conference. SICE 2002. doi: https://doi.org/10.1109/sice.2002.1196548

[5] Soderstrom, T., Stoica, P. (2002). Instrumental variable methods for system identification. Circuits, Systems, and Signal Processing, 21 (1), 1-9. doi: https://doi.org/10.1007/bf01211647

[6] Astrom, K. J., Hang, C. C., Lim, B. C. (1994). A new Smith predictor for controlling a process with an integrator and long dead-time. IEEE Transactions on Automatic Control, 39 (2), 343-345. doi: https:// doi.org/10.1109/9.272329

[7] Hongdong, Z., Ruixia, L., Huihe, S. (2004). Control for integrating processes based on new modified smith predictor. Control 2004, University of Bath.

[8] Kealy, T., O’Dwyer, A. (2002). Comparison of Open- and Closed-loop Process Identification Techniques In The Time-Domain. Proceedings of the 3rd Wismarer Automatisierungssymposium. Wismar.

[9] Mamat, R., Fleming, P. J. (1995). Method for on-line identification of a first order plus dead-time process model. Electronics Letters, 31 (15), 1297-1298. doi: https://doi.org/10.1049/el:19950865

[10] Verhaegen, M., Verdult, V. (2012). Filtering and System Identification: A Least Squares Approach. Cambridge University Press, 422. 